\title{
Waist-to-height ratio as a predictor of serum testosterone in ageing men with symptoms of androgen deficiency
}

\author{
Carolyn A Allan ${ }^{1,2}$, Roger E Peverill ${ }^{3}$, Boyd JG Strauss ${ }^{4}$, Elise A Forbes ${ }^{1}$ and Robert I McLachlan ${ }^{1,2}$
}

The decline in serum testosterone in ageing men may be mediated in part by obesity; however, it is uncertain which measure of adiposity is most closely associated with testosterone levels. We have examined the relationships of age, adiposity and testosterone levels in ageing men with symptoms consistent with hypoandrogenism but who were otherwise in good health. We conducted a cross-sectional study of non-smoking men aged $\geqslant 54$ years recruited from the community and who were free of cancer or serious medical illness. Height $(\mathrm{Ht})$, weight and waist circumference (WC) were measured, and body mass index (BMI) and waist-to-height (WHt) ratio were calculated. Two morning blood samples were collected for measurement of total testosterone (TT), sex hormone binding globulin (SHBG) and luteinizing hormone (LH). Free testosterone (cFT) was calculated. Multivariate linear regression analysis was performed to assess their relationship with measures of adiposity. Two hundred and seven men aged 54-86 years were studied. On univariate analysis WHt ratio was more strongly correlated with TT and cFT than either WC or BMI. Furthermore, in models of TT and cFT, the addition of Ht to WC resulted in an increase in the magnitude of the regression coefficients for both WC (inverse correlate) and $\mathrm{Ht}$ (positive correlate), with the contributions of both WC and Ht both being significant $(\boldsymbol{P}<0.05$ for all). In conclusion, WHt ratio is the best anthropometric predictor of both TT and cFT in this group of healthy but symptomatic ageing men.

Asian Journal of Andrology (2011) 13, 424-431; doi:10.1038/aja.2011.13; published online 11 April 2011

Keywords: Ageing; androgen; male; obesity

\section{INTRODUCTION}

A significant proportion of elderly men have a testosterone level which is below the normal range seen in young men. ${ }^{1}$ Low testosterone levels in ageing men may result in symptoms of hypoandrogenism and such symptoms may therefore be responsive to testosterone replacement. ${ }^{2,3}$ Furthermore, low testosterone has been reported to be an independent predictor of cardiovascular disease, stroke, mortality and Alzheimer's disease, ${ }^{4-10}$ raising the possibility that there could also be prognostic advantages from testosterone replacement. However, the role of testosterone therapy in the ageing male is controversial and remains the subject of ongoing research., ${ }^{2,3}$ Moreover, defining biochemical hypoandrogenism in ageing men is complex, not only because comparison with testosterone levels in young men may not be appropriate ${ }^{1}$ but also because of the recognized effects on testosterone of smoking, ${ }^{11,12}$ poor general health status, ${ }^{12,13}$ and obesity. ${ }^{12-15}$ There is also uncertainty about how best to take obesity into account given recent data that waist circumference (WC) may be a better predictor of the testosterone level than body mass index (BMI) ${ }^{15}$ An additional issue is whether previous findings in population studies regarding adiposity and testosterone are relevant to that group of symptomatic ageing men who are most likely to be considered for testosterone replacement.

In this study, we have examined the relationships of ageing, adiposity and testosterone levels in a highly select group of ageing men (over the age of 54 years) who were recruited on the basis of having symptoms consistent with hypoandrogenism but who were non-smokers and otherwise in good health. Subjects were also excluded if they had a BMI $\geqslant 35 \mathrm{~kg} \mathrm{~m}^{-2}$ because of the documented association of severe obesity with hypogonadotrophic hypogonadism. ${ }^{16-18}$ We investigated whether WC was a better predictor of testosterone than BMI in our cohort and, given increasing evidence of the value of indexing WC to height (Ht) as waist-to-height ratio (WHt ratio), ${ }^{19-21}$ we also examined the utility of WHt ratio for prediction of the testosterone level. Furthermore, given the important regulating effect of sex hormone binding globulin (SHBG) on testosterone levels, and the complex relation of SHBG with age and adiposity, ${ }^{22}$ we investigated the relationship of BMI, WC and WHt ratio with testosterone after adjusting for SHBG.

\section{MATERIALS AND METHODS}

Subjects

Men aged 55 years and over were invited by community advertisement to take part in a study on the effects of testosterone therapy. ${ }^{23,24}$ Participants were Caucasian non-smokers who were in good general health and who had symptoms consistent with testosterone deficiency in each of the categories of mood and cognition (decreased sense of well being, lack of motivation, deterioration in work performance, lethargy, low mood, low self-esteem, difficulties with short-term memory, tendency to fall asleep and frequent headaches), muscle function and body composition (decreased physical energy or 
endurance, diminished muscle mass and strength, abdominal obesity, loss of height) and sexuality (decreased interest or desire for sex, reduced quality of sexual activity, poor erectile function, limited quality of orgasm, and absent or decreased nocturnal erections). Men were excluded if they reported any of the following: excessive alcohol intake, a history of malignancy (excluding non-melanoma skin cancer), a serious chronic medical illness including diabetes mellitus and sleep apnoea, prostate cancer or clinically significant benign prostate disease. They were also excluded if they reported or were subsequently found to have greater than class I obesity $\left(B M I \geqslant 35 \mathrm{~kg} \mathrm{~m}^{-2}\right.$ ). Men who had received testosterone therapy in the previous 12 months or had ever had a testosterone implant were not included. Eligible subjects had basic anthropometry (height, weight and WC) measured by the same research nurse, and two morning blood samples were collected between 8 and 11 a.m. (taken approximately 2 weeks apart) for measurement of total testosterone (TT), SHBG and luteinizing hormone ( $\mathrm{LH}$ ). The mean of the two values was calculated, but if there was more than a twofold difference in TT values then a third sample was collected and the mean of the three values was used $(n=5)$. The research project was approved by the Southern Health Human Research Ethics Committee and all subjects gave signed consent. Subjects were studied between May 2001 and February 2003.

\section{Assay details}

TT was measured by automated chemiluminescent immunoassay using an ACS:180 Automated Chemiluminescence System (Chiron Diagnostic, East Walpole, MA, USA) (inter-assay coefficient of variation 7.9\%; nor-

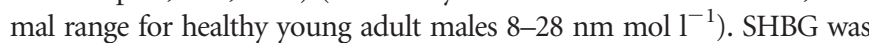
determined on an Immulite Analyzer (Immulite 1000 Immunoassay, Siemens Healthcare Diagnostics, Deerfield, IL, USA) (inter-assay coefficient of variation 7.9\%). Free testosterone (cFT) was calculated as previously described. ${ }^{25} \mathrm{LH}$ was measured by microparticle enzyme immunoassay (MEIA; inter-assay coefficient of variation 6.4\%; normal range 1.4-8.0 $\left.\mathrm{IU}^{-1}\right)$.

\section{Anthropometry}

Ht was determined by a stadiometer calibrated to the nearest $0.1 \mathrm{~cm}$ and weight was measured on scales calibrated to $0.1 \mathrm{~kg}$ to calculate BMI (ratio of body weight in $\mathrm{kg}$ to height in $\mathrm{m}^{2}$ ). ${ }^{26} \mathrm{WC}$ was measured, according to WHO guidelines, at the midpoint distance between the costal margin and iliac crest in the mid-axillary line on the dominant side. ${ }^{26}$ WHt ratio was calculated by dividing waist $(\mathrm{cm})$ by height $(\mathrm{cm})$.

\section{Statistical analysis}

All statistical analyses were performed using SYSTAT V12 (Systat Software, Inc., Chicago, IL, USA). Continuous data are presented as mean \pm s.d. TT, cFT, SHBG, WC, BMI and WHt ratio met skewness and kurtosis criteria for normal distribution. LH levels were not normally distributed but there was no difference in the correlations of $\mathrm{LH}$ after normalisation by $\log$ transformation so for simplicity the nontransformed data are shown. Linear regression analysis was performed to assess the relationship of TT, cFT, SHBG and LH with age, BMI, WC, $\mathrm{Ht}$ and WHt ratio. On review of scatter plots and residuals, eight potential outliers were identified and final results shown have excluded these outliers. However, in analyses performed with the inclusion of these subjects, there was no significant difference in the observed relationships. Multiple linear regression models were constructed to determine whether correcting WC for $\mathrm{Ht}$ made an independent contribution to the prediction of SHBG, cFT or TT. For the multivariate models the regression coefficients, standard errors and standard coefficients as well as the $r^{2}$ adjusted for inclusion of multiple dependent variables are shown. Statistical significance was defined as $P<0.05$.

\section{RESULTS}

Two hundred and seven men aged 54-86 years were included in the analysis. The characteristics of the subjects are detailed in Table 1. On linear regression analysis, there was no relation of age with BMI, WC or WHt ratio, but there was a weak inverse correlation between age and Ht $(r=-0.14, P=0.047)$ and a borderline significant inverse correlation between age and weight $(r=-0.13, P=0.054)$. As expected, there were moderate positive correlations of BMI with WC $(r=0.86$, $P<0.001)$ and BMI with WHt ratio $(r=0.88, P<0.001)$.

The scatter plots showing the correlations of TT, cFT, SHBG and LH with age are shown in Figure 1. Age was positively correlated with SHBG and LH, inversely correlated with cFT, but not related to TT. The scatter plots showing the correlations of TT and cFT with BMI, WC and WHt ratio are shown in Figure 2. TT and cFT were both inversely correlated with BMI, WC and WHt ratio. Based on the $r$ values, the correlations of TT and cFT with WC were slightly stronger than the respective correlations with BMI, while the correlations of WHt ratio with TT and cFT were stronger than their correlations with WC. Furthermore, the correlations of BMI, WC and WHt ratio with TT were stronger than their correlations with cFT. LH was not correlated with any of the anthropometric measures (data not shown).

The regression and standard coefficients for the univariate linear regression relationships of SHBG with age, BMI, WC, $\mathrm{Ht}$ and $\mathrm{WHt}$ ratio are shown in Table 2. SHBG was inversely correlated with BMI, WC and WHt ratio, with WC having the highest $r$ value. A series of multivariate models of SHBG which investigated the contribution of age with BMI and WC, and also the addition of $\mathrm{Ht}$ to $\mathrm{WC}$ with and without the inclusion of age, are shown in Table 2. Age was a significant positive correlate of SHBG independent of anthropometric measures, and BMI and WC were both independent inverse correlates of SHBG when individually included with age. The variability of SHBG explained by the model including age and WC was slightly more than the model including age and BMI (12\% versus $9 \%)$. There was no improvement in the prediction of SHBG when Ht was added to either WC or the combination of age and WC.

The regression and standard coefficients for the univariate linear regression relationships of $\mathrm{cFT}$ with age, $\mathrm{BMI}, \mathrm{WC}, \mathrm{Ht}$ and $\mathrm{WH}$ ratio are shown in Table 3. A series of multivariate models of cFT which investigated the effects of adding age to BMI and $\mathrm{WC}$ and $\mathrm{Ht}$ and the combination of age and Ht to WC are also shown in Table 3. Age remained a significant inverse correlate of cFT when combined with any of the anthropometric measures. BMI and WC both remained

Table 1 Characteristics of the study cohort $(n=207)$

\begin{tabular}{|c|c|c|}
\hline Variables & Mean \pm s.d. & Range \\
\hline Age (years) & $63.7 \pm 6.7$ & $54-86$ \\
\hline $\mathrm{Ht}(\mathrm{cm})$ & $175.2 \pm 7.0$ & 158.0-194.5 \\
\hline Weight (kg) & $85.1 \pm 11.6$ & $57.2 \pm 115.5$ \\
\hline $\mathrm{BMI}\left(\mathrm{kg} \mathrm{m}^{-2}\right)$ & $27.7 \pm 3.2$ & $20.5-34.9$ \\
\hline WC (cm) & $99.7 \pm 8.9$ & $77-125$ \\
\hline WHt ratio & $0.57 \pm 0.05$ & $0.44-0.72$ \\
\hline $\mathrm{TT}\left(\mathrm{nmol} \mathrm{I}^{-1}\right)$ & $13.7 \pm 4.0$ & $4.7-28.1$ \\
\hline cFT (pmol I-1) & $287 \pm 72$ & $119-492$ \\
\hline SHBG $\left(n m o l I^{-1}\right)$ & $36.9 \pm 12.4$ & $7.0-71.8$ \\
\hline $\mathrm{LH}\left(\mathrm{IU} \mathrm{I}^{-1}\right)$ & $5.7 \pm 3.3$ & $0.8-20.5$ \\
\hline
\end{tabular}

Abbreviations: $\mathrm{BMI}$, body mass index; $\mathrm{CFT}$, free testosterone was calculated; $\mathrm{Ht}$, height; LH, luteinizing hormone; TT, total testosterone; SHBG, sex hormone biding globulin; WC, waist circumference; WHt, waist-to-height; s.d., standard deviation. 


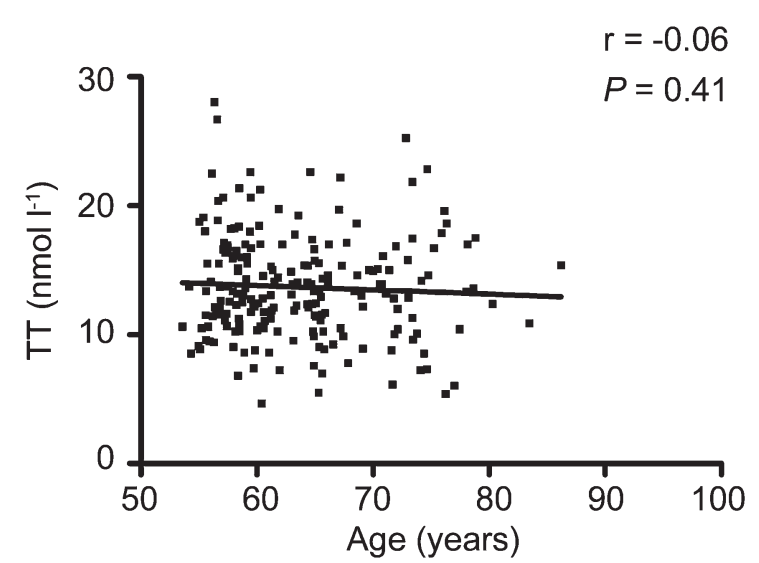

$r=0.24$

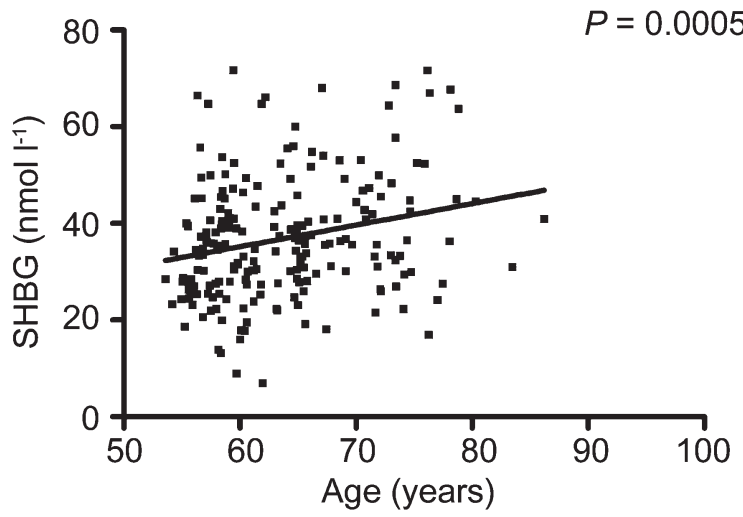

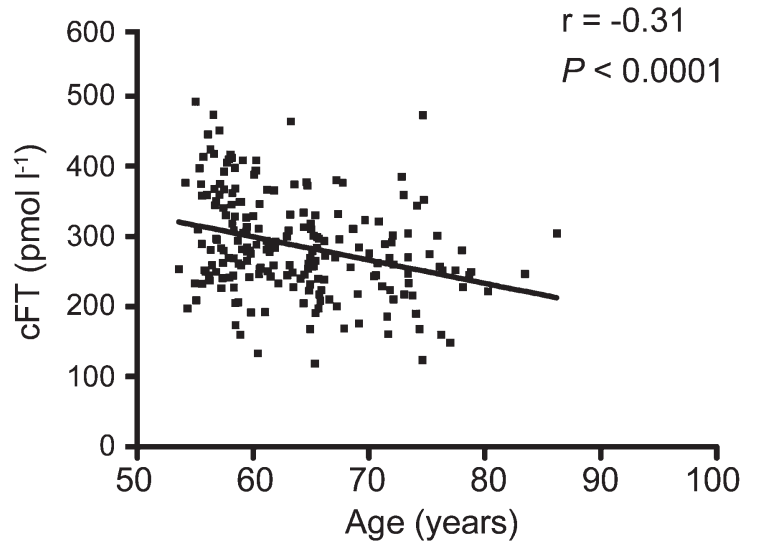

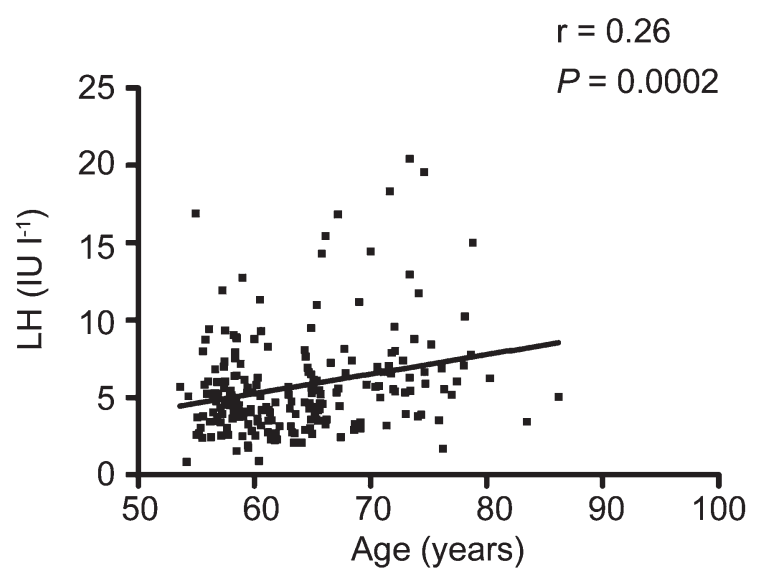

Figure 1 Scatter plots showing correlation of age with total testosterone (TT) (a), calculated free testosterone (cFT) (b), sex hormone biding globulin (SHBG) (c) and luteinizing hormone (LH) (d) levels for all subjects $(n=207)$.

independent inverse predictors of cFT when individually combined with age, whereas height was no longer significant (result not shown). The model of cFT with age and WC had a slightly higher adjusted $r^{2}$ than the model with age and BMI. Combining Ht with WC in a model of cFT resulted in an increase in the magnitude of the partial correlation coefficients of both WC (inverse) and Ht (positive) and the contributions of both WC and Ht were significant. A similar pattern for prediction of $\mathrm{cFT}$ with $\mathrm{WC}$ and $\mathrm{Ht}$ was observed after the inclusion of age in the model, with the addition of $\mathrm{Ht}$ to age and $\mathrm{WC}$ resulting in a further increase in the adjusted $r^{2}$. After inclusion of BMI with age, WC and Ht in a model of cFT, age $(\beta=-0.26, P<0.001)$, WC $(\beta=-0.42, P=0.007)$ and $\mathrm{Ht}(\beta=0.22, P=0.006)$ were predictors of cFT but BMI was not $(P=0.20)$. SHBG was not correlated with $\mathrm{cFT}$ on univariate analysis and the inclusion of SHBG in multivariate models of cFT did not add to the prediction of cFT (results not shown).

The regression and standard coefficients for the univariate linear regression relationships of TT with age, $\mathrm{BMI}, \mathrm{WC}, \mathrm{Ht}$, WHt ratio and SHBG are shown in Table 4. A series of multivariate models of TT which investigated the effects of adding WC and BMI to SHBG, of adding $\mathrm{Ht}$ to WC with and without SHBG and of adding Ht to the combination of WC, SHBG and age are also shown in Table 4. Models of TT including WC had a slightly higher adjusted $r^{2}$ than models including BMI. WC and Ht were independent predictors of TT when included together and there was an increase in the regression coefficients of both variables when they were combined, with the contribution of Ht becoming significant. After inclusion of BMI with WC and Ht in a model of TT, WC and Ht were predictors of TT $(\beta=-0.57$, $P<0.001 ; \beta=0.23, P=0.003)$, but BMI was not $(P=0.13)$.

Age was not a significant univariate predictor of TT and remained nonsignificant after including either BMI or WC in the models (results not shown). However, age became a significant inverse correlate of TT after SHBG was included in the model, suggesting that the lack of relation of TT with age in the univariate analysis was due to the positive correlation of SHBG with both age and TT. In the multivariate models including age and SHBG, WC was a significant inverse correlate of TT. Furthermore, the addition of Ht in the models of TT which included WC and SHBG or WC, SHBG and age resulted in an increase in the magnitude of the regression coefficients for both $\mathrm{WC}$ and $\mathrm{Ht}$ and an improvement in the adjusted $r^{2}$, with the contribution of $\mathrm{Ht}$ becoming significant.

\section{DISCUSSION}

Inverse relationships of BMI and WC with TT and CFT have been previously documented in unselected cohorts of adult men. ${ }^{11-15,27}$ Our findings demonstrate a similar relationship of these markers of adiposity with TT and cFT in a highly select group of ageing men (over the age of 54 years), otherwise healthy except for symptoms consistent with, although not specific for, androgen deficiency. Furthermore, we report for the first time that adjusting $\mathrm{WC}$ for height (WHt ratio) improves the prediction of TT and cFT compared with either BMI or WC alone.

While multivariate analyses in large population derived crosssectional studies allow adjustment for potential confounding factors, 

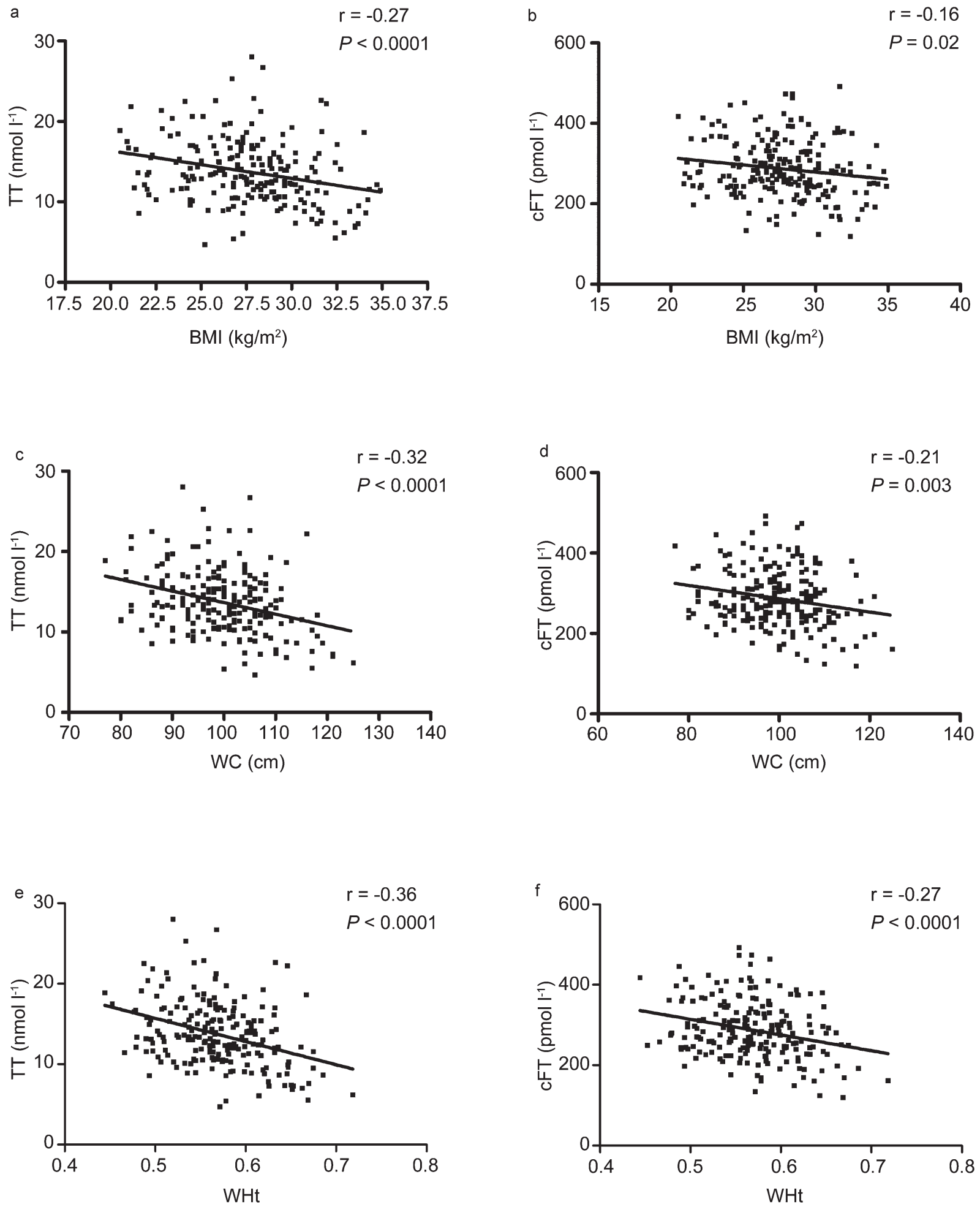

Figure 2 Correlations of total testosterone (TT) (a, c, e) and calculated free testosterone (cFT) (b, d, f) with body mass index (BMI), waist circumference (WC) and waist-to-height $(\mathrm{WHt})$ ratio $(n=207)$.

such adjustment may not be adequate when there are complex relationships between multiple factors or if there is a subgroup within the population in which the behaviour is divergent from the group as a whole. In such circumstances, analysis of a specific subgroup, after exclusion of subjects with confounding factors, can provide complementary information to the population based studies. In the selective process for our cohort we excluded men with a number of potential confounding factors. Men with major illnesses were excluded as these are not only known to be associated with lower $\mathrm{TT},{ }^{13,28,29}$ but are known to have varying relationships with adiposity. 
Table 2 Progression of regression relations predicting SHBG from BMI with the addition of age and from WC with the addition of age and Ht

\begin{tabular}{|c|c|c|c|c|c|}
\hline Model & Regression coefficient & s.e. & $\beta$ (standard coefficient) & $P$ & Adjusted $\mathrm{r}^{2}$ \\
\hline Age & 0.445 & 0.125 & 0.241 & $<0.001$ & 0.054 \\
\hline BMI & -0.868 & 0.268 & -0.221 & 0.001 & 0.044 \\
\hline WC & -0.351 & 0.094 & -0.252 & $<0.001$ & 0.059 \\
\hline WHt ratio & -58.427 & 16.934 & -0.234 & 0.001 & 0.050 \\
\hline Age $+\mathrm{BMI}$ & & & & & 0.092 \\
\hline Age & 0.423 & 0.123 & 0.229 & 0.001 & \\
\hline Age & 0.460 & 0.121 & 0.250 & $<0.001$ & \\
\hline WC & -0.362 & 0.091 & -0.260 & $<0.001$ & \\
\hline $\mathrm{WC}+\mathrm{Ht}$ & & & & & 0.055 \\
\hline WC & -0.358 & 0.098 & -0.257 & $<0.001$ & \\
\hline $\mathrm{Ht}$ & 0.030 & 0.129 & 0.016 & 0.816 & \\
\hline $\mathrm{Age}+\mathrm{WC}+\mathrm{Ht}$ & & & & & 0.116 \\
\hline
\end{tabular}

Abbreviations: BMI, body mass index; Ht, height; SHBG, sex hormone biding globulin; WC, waist circumference; WHt, waist-to-height; s.e., standard error.

For example, cancer is associated with lower $\mathrm{TT},{ }^{28}$ but may also result in a lower BMI, whereas type 2 diabetes is accompanied by a lower $\mathrm{TT},{ }^{29-31}$ but more likely to occur in subjects with increased BMI and WC. ${ }^{32}$ We also excluded men who were current smokers as this is associated with increases in TT, SHBG and LH, ${ }^{11-13,29,33,34}$ as well as being associated with lower whole body and abdominal percentage fat mass. ${ }^{35}$ Furthermore, by excluding men with severe obesity, which can result in hypogonadotropic hypogonadism, ${ }^{16-18}$ we were able to reduce the chance that suppression of $\mathrm{LH}$ was also contributing to a reduction in testosterone levels in men with increased adiposity.

Obesity is well recognized to be associated with lower testosterone levels, and although obesity is also more common with ageing, ${ }^{36-39}$ the inverse relationship of testosterone with BMI is independent of age. $^{12,13,15,40}$ In the present study, there were inverse correlations between cFT, TT and either BMI or WC. Overall for each unit increase in BMI, there was a $2 \%$ fall in TT and cFT, and for each $10 \mathrm{~cm}$ increment in WC, TT and cFT levels declined by 7\%. The magnitude of this relationship between increasing BMI and decreasing TT is similar to that described in the Massachusetts Male Ageing Study. ${ }^{29}$

Svartberg et al. ${ }^{15}$ reported a closer inverse relationship of TT and cFT with WC than BMI and that WC was an independent predictor of TT and cFT even after adjusting for BMI, suggesting a closer relationship of lower levels of testosterone with abdominal than general adiposity. Although the correlation of WC with TT and cFT we observed in our cohort was slightly stronger than the relationship of BMI with TT and CFT on univariate analysis, the benefit of WC compared with BMI for the prediction of $\mathrm{cFT}$ after adjusting for age was minimal. The apparent difference in findings between our study and that of Svartberg et al. could be due to differences between the study groups which could have affected the relationships of BMI or WC with testosterone. Of particular relevance, the study group of Svartberg et al. had a wider age range (25-84 years) and demonstrated an increase in WC with age up to the age of 40 years. An inherent limitation of BMI as a marker of general adiposity is that it also reflects muscle mass, ${ }^{26}$ and

Table 3 Progression of regression relations predicting cFT from WC as $\mathrm{Ht}$ and age are added to the model

\begin{tabular}{|c|c|c|c|c|c|}
\hline Model & Regression coefficient & s.e. & $\beta$ (standard coefficient) & $P$ & Adjusted $\mathrm{r}^{2}$ \\
\hline Age & -3.313 & 0.706 & -0.312 & $<0.001$ & 0.093 \\
\hline $\mathrm{BMI}$ & -3.573 & 1.564 & -0.158 & 0.023 & 0.020 \\
\hline WC & -1.651 & 0.549 & -0.205 & 0.003 & 0.038 \\
\hline $\mathrm{Ht}$ & 1.488 & 0.729 & 0.141 & 0.042 & 0.015 \\
\hline WHt ratio & -390.541 & 96.660 & -0.272 & $<0.001$ & 0.069 \\
\hline Age + BMI & & & & & 0.119 \\
\hline Age & -3.422 & 0.697 & -0.322 & $<0.001$ & \\
\hline $\mathrm{BMI}$ & -3.998 & 1.485 & -0.176 & 0.008 & \\
\hline Age $+W C$ & & & & & 0.13 \\
\hline Age & -3.247 & 0.693 & -0.305 & $<0.001$ & \\
\hline WC & -1.574 & 0.523 & -0.196 & 0.003 & \\
\hline $\mathrm{WC}+\mathrm{Ht}$ & & & & & 0.075 \\
\hline WC & -2.111 & 0.559 & -0.263 & $<0.001$ & \\
\hline $\mathrm{Ht}$ & 2.236 & 0.734 & 0.212 & 0.003 & \\
\hline $\mathrm{Age}+\mathrm{WC}+\mathrm{Ht}$ & & & & & 0.148 \\
\hline Age & -2.986 & 0.692 & -0.281 & $<0.001$ & \\
\hline WC & -1.944 & 0.538 & -0.242 & $<0.001$ & \\
\hline $\mathrm{Ht}$ & 1.768 & 0.712 & 0.168 & 0.014 & \\
\hline
\end{tabular}

Abbreviations: BMI, body mass index; cFT, free testosterone was calculated; Ht, height; WC, waist circumference; WHt, waist-to-height; s.e., standard error. 
Table 4 Progression of regression relations predicting TT from WC and BMI as SHBG, age and Ht are added to the model

\begin{tabular}{|c|c|c|c|c|c|}
\hline & Regression coefficient & s.e. & $\beta$ (standard coefficient) & $P$ & Adjusted $\mathrm{r}^{2}$ \\
\hline Age & -0.034 & 0.042 & -0.057 & 0.42 & 0 \\
\hline $\mathrm{BMI}$ & -0.345 & 0.086 & -0.271 & $<0.001$ & 0.069 \\
\hline WC & -0.145 & 0.030 & -0.320 & $<0.001$ & 0.098 \\
\hline WHt ratio & -29.0 & 5.3 & -0.358 & $<0.001$ & 0.124 \\
\hline SHBG & 0.220 & 0.017 & 0.678 & $<0.001$ & 0.457 \\
\hline $\mathrm{WC}+\mathrm{Ht}$ & & & & & 0.121 \\
\hline SHBG+age & & & & & 0.515 \\
\hline SHBG & 0.241 & 0.016 & 0.741 & $<0.001$ & \\
\hline Age & -0.141 & 0.030 & -0.236 & $<0.001$ & \\
\hline $\mathrm{SHBG}+\mathrm{BMI}$ & & & & & 0.469 \\
\hline SHBG & 0.211 & 0.017 & 0.650 & $<0.001$ & \\
\hline BMI & -0.16 & 0.067 & -0.125 & 0.017 & \\
\hline SHBG & 0.208 & 0.016 & 0.641 & $<0.001$ & \\
\hline WC & -0.092 & 0.024 & -0.203 & $<0.001$ & \\
\hline Height & 0.095 & 0.030 & 0.160 & 0.002 & \\
\hline $\mathrm{SHBG}+\mathrm{age}+\mathrm{BMI}$ & & & & & 0.519 \\
\hline SHBG & 0.230 & 0.017 & 0.706 & $<0.001$ & \\
\hline Age & -0.141 & 0.030 & -0.235 & $<0.001$ & \\
\hline $\mathrm{BMI}$ & -0.162 & 0.063 & -0.127 & 0.011 & \\
\hline $\mathrm{SHBG}+$ age + WC & & & & & 0.531 \\
\hline SHBG & 0.228 & 0.017 & 0.703 & $<0.001$ & \\
\hline Age & -0.133 & 0.030 & -0.222 & $<0.001$ & \\
\hline WC & -0.062 & 0.022 & -0.137 & 0.006 & \\
\hline $\mathrm{SHBG}+$ age $+\mathrm{WC}+\mathrm{Ht}$ & & & & & 0.543 \\
\hline SHBG & 0.226 & 0.016 & 0.696 & $<0.001$ & \\
\hline
\end{tabular}

Abbreviations: BMI, body mass index; Ht, height; TT, total testosterone; SHBG, sex hormone biding globulin; WC, waist circumference; WHt, waist-to-height; s.e., standard error.

this may have assumed greater significance in the study of Svartberg et al. because of the inclusion of young men. Indeed, one other study which only included men aged $>40$ years did not find WC to be an independent contributor to the prediction of testosterone after adjusting for BMI. ${ }^{12}$

WHt ratio was the best of the anthropometric variables in predicting TT and cFT in our study, even after adjustment for age. When WC and height were included in multivariate models for either TT or cFT, WC was inversely correlated and height was positively correlated. Moreover, there was an increase in the partial correlation coefficients for both WC and height when both were included in the same model, indicating that the inclusion of height also improved the contribution of WC to the model. Adjusting for Ht was considered in this analysis because a number of epidemiological studies have suggested that $\mathrm{WHt}$ ratio is a better predictor of cardiovascular risk factors ${ }^{19,41}$ and cardiovascular risk ${ }^{20,42}$ than either BMI or WC. It is also relatively easy to use for the assessment of obesity as a cutoff of 0.5 can be used independent of age, gender or racial origin. ${ }^{21} \mathrm{We}$ are not aware of any other studies which have investigated the relationship of WHt ratio with testosterone, but such an analysis could be easily performed retrospectively in previous studies in which WC was measured as Ht data will almost certainly also be available.
The concentration of SHBG is a major determinant of TT, ${ }^{22}$ as alterations of SHBG in men with a functional hypothalamopituitary-gonadal axis result in alterations in TT via feedback regulation of LH secretion to maintain stability of free testosterone. However, this axis may not be functioning normally in older men and changes in SHBG may therefore also influence free testosterone levels. ${ }^{43,44}$ Levels of SHBG (and TT) are influenced by genetic polymorphisms affecting $\mathrm{SHBG},{ }^{44}$ with even further complexity in the relationship between SHBG and testosterone in ageing men as SHBG increases with age, ${ }^{27}$ but decreases with rising adiposity. ${ }^{15}$ In view of the above issues with SHBG, in considering the effects of age and adiposity on testosterone it is important that SHBG levels are also taken into account. Similar to previous studies, ${ }^{15}$ SHBG was more closely related to WC than BMI in our cohort and it was independently related to $\mathrm{WC}$ even after adjusting for BMI (result not shown). In contrast to TT and cFT, there was no improvement in the prediction of SHBG with the addition of Ht to WC. There was no evidence of an effect of SHBG on cFT in the present study as SHBG was not correlated with $\mathrm{cFT}$ on linear regression analysis. While SHBG was the major determinant of TT, the inclusion of SHBG in the model of TT did not alter the independent contribution of WC or the further independent contribution of $\mathrm{Ht}$ when added to WC. 
The relation between testosterone and obesity appears to be bidirectional, with low testosterone being both a cause as well as a consequence of obesity. ${ }^{45}$ However, as far as short- and medium-term effects are concerned, while testosterone replacement has only been shown to have a minor effect on adiposity, ${ }^{23,46,47}$ major weight loss can result in marked increases in SHBG, cFT and TT levels. ${ }^{48,49}$ Moreover, achievement of near-normal body weight can lead to normalisation of SHBG concentrations in massively obese men. ${ }^{50}$ Nevertheless, determination of the relative importance of these bidirectional effects in our cohort is not possible as there could be differences in short- and long-term relationships between adiposity and testosterone.

A causal association of ageing and adiposity with lower serum testosterone levels could involve changes at the level of the hypothalamus, pituitary or testes. The LH level gives a partial guide to the cause of the lower testosterone as an increase in LH suggests impairment of testicular function whereas a lack of elevation of LH in the setting of a low testosterone implies a failure at the hypothalamus/ pituitary level. Findings in the present study are consistent with previous studies which have shown that LH increases with ageing but does not increase with increasing adiposity, suggesting that adiposity has effects on testosterone at the hypothalamus/pituitary level. ${ }^{13}$

Most cross-sectional and the several available longitudinal studies have demonstrated a gradual linear age-related decrease in levels of FT, and to a lesser extent in TT, after the fourth decade. ${ }^{12,13,27,51-54}$ Consistent with these previous findings, an inverse relationship between age and cFT levels was seen in our cohort and this also remained significant after adjusting for BMI, WC or WHt ratio. In contrast, no association between TT and age was evident in our cohort on univariate analysis and there are several possible explanations for this finding. A lack of correlation between TT and age may have been contributed to the relatively narrow age range of our subjects, or could have been a false negative finding due to our small sample size, in conjunction with the relatively smaller effect of age on TT compared with cFT seen in previous studies. ${ }^{12,15,27}$ An alternative explanation is that we limited our study group to those subjects who were at most mildly obese (BMI $\leqslant 35 \mathrm{~kg} \mathrm{~m}^{-2}$ ) as it has previously been reported that, after adjusting for body fat mass, an inverse relationship between age and TT is no longer evident. ${ }^{55}$ However, and possibly most important, it remains unclear whether age is actually an independent predictor of a lower TT, as after adjusting for comorbidities no relationship of age with TT was found in either the European Male Ageing Study ${ }^{13}$ or the Florey Adelaide Male Ageing Study. ${ }^{33}$ Including SHBG in the multivariate analysis of TT provided additional insight into the relationship of age with TT as age became a significant predictor of a lower TT after adjusting for SHBG and also remained significant with the inclusion of either BMI, WC or WHt ratio with SHBG in the model. This suggests that the lack of relationship of TT with age on univariate analysis is in part due to the confounding effect of the positive relationship of age with SHBG.

A strength of our study was that the mean of the measurements from at least two blood samples collected on different days was used in the analysis. This will have minimized the effect of the day-to-day/ week-to-week variability in testosterone levels which has been previously reported and can lead to individual measurements of testosterone concentrations varying between the eugonadal and hypogonadal ranges. ${ }^{3,56}$ A further strength of the current study was that the blood was collected in the morning for measurement of serum testosterone as testosterone levels have a diurnal variation, with higher levels of TT and cFT occurring in the morning. ${ }^{3,15}$ A limitation of the study was the ability to define hypoandrogenism in this cohort. ${ }^{2,3}$ Although the screening questionnaire sought symptoms suggestive of androgen deficiency, these are nonspecific and may not reflect serum testosterone levels.

Recent guidelines regarding the investigation, treatment and monitoring of late-onset hypogonadism highlight that there are a number of limitations in our current knowledge. ${ }^{2,3}$ This is the first time the relationship between measures of adiposity and serum testosterone has been studied specifically in a cohort of healthy ageing men with symptoms consistent with hypoandrogenism and without severe obesity. Our results suggest that, of the anthropometric measures compared in this study, WHt ratio is the best predictor of both TT and $\mathrm{cFT}$ in this group. As BMI, WC (and probably also WHt ratio) may change as a function of age, ${ }^{35}$ failure to adjust for adiposity may lead to an overestimation of the age-associated decline in serum testosterone in older men. Given the increasing prevalence of obesity ${ }^{26}$ and the growing use of testosterone therapy by ageing men, ${ }^{57}$ our findings further underscore the need to better understand the cause and effect nature of the relationships between obesity, serum TT and cFT levels, and the role of testosterone therapy in obese men.

\section{AUTHOR CONTRIBUTIONS}

CAA conceived of the study, participated in its design, coordination, data collection and analysis, and helped to draft the manuscript. REP participated in study design, devised the data analysis protocol, performed the statistical analysis and helped to draft the manuscript. BJGS conceived of the study, participated in its design and helped to draft the manuscript. EAF participated in the study coordination and data collection, and assisted in manuscript preparation. RIMcL conceived of the study, participated in its design and helped to draft the manuscript. All authors read and approved the final manuscript.

\section{COMPETING FINANCIAL INTERESTS}

The authors would declare no competing financial interests.

\section{ACKNOWLEDGMENTS}

Dr Allan received an Australian Postgraduate Award 2000 (Monash University, No. 10506136) and an NH\&MRC Medical Postgraduate Research Scholarship 2001-2004 (No. 169015). Professor McLachlan is a Principal Research Fellow, NH\&MRC (No. 441103). This work was supported by Mayne Pharma Australia Pty Ltd. The authors acknowledge the assistance of Antony Ugoni. Prince Henry's Institute is supported by the Victorian Government's Operational Infrastructure Support Program. Prince Henry's Institute Data Audit 10-16.

1 Vermeulen A. Andropause. Maturitas 2000; 34: 5-15.

2 Wang C, Nieschlag E, Swerdloff R, Behre HM, Hellstrom WJ et al. Investigation, treatment, and monitoring of late-onset hypogonadism in males: ISA, ISSAM, EAU, EAA, and ASA recommendations. J Androl 2009; 30: 1-9.

3 Bhasin S, Cunningham GR, Hayes FJ, Matsumoto AM, Snyder PJ et al. Testosterone therapy in adult men with androgen deficiency syndromes: an Endocrine Society clinical practice guideline. J Clin Endocrinol Metab 2006; 91: 1995-2010.

4 Hak AE, Witteman JC, de Jong FH, Geerlings MI, Hofman A et al. Low levels of endogenous androgens increase the risk of atherosclerosis in elderly men: the Rotterdam study. J Clin Endocrinol Metab 2002; 87: 3632-9.

5 Svartberg J, von Mühlen D, Mathiesen E, Joakimsen O, Bønaa KH et al. Low testosterone levels are associated with carotid atherosclerosis in men. J Intern Med 2006; 259: 576-82.

6 Laughlin GA, Barrett-Connor E, Bergstrom J. Low serum testosterone and mortality in older men. J Clin Endocrinol Metab 2008; 93: 68-75.

7 Araujo AB, Kupelian V, Page ST, Handelsman DJ, Bremner WJ et al. Sex steroids and all-cause and cause-specific mortality in men. Arch Intern Med 2007; 167: 1252-60.

8 Khaw KT, Dowsett M, Folkerd E, Bingham S, Wareham N et al. Endogenous testosterone and mortality due to all causes, cardiovascular disease, and cancer in men. European Prospective Investigation into Cancer in Norfolk (EPIC-Norfolk) Prospective Population Study. Circulation 2007; 116: 2694-701. 
9 Yeap BB, Hyde Z, Almeida OP, Norman PE, Chubb SA et al. Lower testosterone levels predict incident stroke and transient ischemic attack in older men. $J$ Clin Endocrinol Metab 2009; 94: 2353-9.

10 Vikan T, Schirmer H, Njolstad I, Svartberg J. Endogenous sex hormones and the prospective association with cardiovascular disease and mortality in men: the Tromso Study. Eur J Endocrinol 2009; 161: 435-42.

11 Field AE, Colditz GA, Willett WC, Longcope C, McKinlay JB. The relation of smoking, age, relative weight, and dietary intake to serum adrenal steroids, sex hormones, and sex hormone-binding globulin in middle-aged men. J Clin Endocrinol Metab 1994, 79: 1310-6.

12 Muller M, den Tonkelaar I, Thijssen JH, Grobbee DE, van der Schouw YT. Endogenous sex hormones in men aged 40-80 years. Eur J Endocrinol 2003; 149: 583-9.

13 Wu FC, Tajar A, Pye SR, Silman AJ, Finn JD et al. Hypothalamic-pituitary-testicular axis disruptions in older men are differentially linked to age and modifiable risk factors: the European Male Aging Study. J Clin Endocrinol Metab 2008; 93: 2737-45.

14 Ukkola O, Gagnon J, Rankinen T, Thompson PA, Hong Y et al. Age, body mass index, race and other determinants of steroid hormone variability: the HERITAGE Family Study. Eur J Endocrinol 2001; 145: 1-9.

15 Svartberg J, von Mühlen D, Sundsfjord J, Jorde R. Waist circumference and testosterone levels in community dwelling men. The Tromso study. Eur J Epidemiol 2004; 19: 657-63.

16 Strain GW, Zumoff B, Kream J, Strain JJ, Deucher R et al. Mild hypogonadotropic hypogonadism in obese men. Metabolism 1982; 31: 871-5.

17 Strain GW, Zumoff B, Miller LK, Rosner W, Levit C et al. Effect of massive weight loss on hypothalamic-pituitary-gonadal function in obese men. J Clin Endocrinol Metab 1988; 66: 1019-23.

18 Giagulli VA, Kaufman JM, Vermeulen A. Pathogenesis of the decreased androgen levels in obese men. J Clin Endocrinol Metab 1994; 79: 997-1000.

19 Hsieh SD, Muto T. The superiority of waist-to-height ratio as an anthropometric index to evaluate clustering of coronary risk factors among non-obese men and women. Prev Med 2005; 40: 216-20.

20 Gelber RP, Gaziano JM, Orav EJ, Manson JE, Buring JE et al. Measures of obesity and cardiovascular risk among men and women. J Am Coll Cardiol 2008; 52: 605-15.

21 Ashwell M, Hsieh SD. Six reasons why the waist-to-height ratio is a rapid and effective global indicator for health risks of obesity and how its use could simplify the international public health message on obesity. Int J Food Sci Nutr 2005; 56: 303-7.

22 Siiteri PK, Murai JT, Hammond GL, Nisker JA, Raymoure WJ et al. The serum transport of steroid hormones. Recent Prog Horm Res 1982; 38: 457-510.

23 Allan CA, Strauss BJ, Burger HG, Forbes EA, McLachlan RI. Testosterone therapy prevents gain in visceral adipose tissue and loss of skeletal muscle in nonobese aging men. J Clin Endocrinol Metab 2008; 93: 139-46.

24 Allan CA, Forbes EA, Strauss BJ, McLachlan RI. Testosterone therapy increases sexual desire in ageing men with low-normal testosterone levels and symptoms of androgen deficiency. Int J Impot Res 2008; 20: 396-401.

25 Vermeulen A, Verdonck L, Kaufman JM. A critical evaluation of simple methods for the estimation of free testosterone in serum. J Clin Endocrinol Metab 1999; 84: 3666-72.

26 World Health Organization. Obesity: preventing and managing the global epidemic WHO: Geneva, Switzerland, 1997. Technical report no. 894.

27 Gray A, Feldman HA, McKinlay JB, Longcope C. Age, disease, and changing sex hormone levels in middle-aged men: results of the Massachusetts Male Aging Study. J Clin Endocrinol Metab 1991; 73: 1016-25.

28 Svartberg J, Midtby M, Bonaa KH, Sundsfjord J, Joakimsen RM et al. The associations of age, lifestyle factors and chronic disease with testosterone in men: the Tromso Study. Eur J Endocrinol 2003; 149: 145-52.

29 Travison TG, Araujo AB, Kupelian V, O'Donnell AB, McKinlay JB. The relative contributions of aging, health, and lifestyle factors to serum testosterone decline in men. J Clin Endocrinol Metab 2007; 92: 549-55.

30 Svartberg J. Epidemiology: testosterone and the metabolic syndrome. Int J Impot Res 2007; 19: 124-8.

31 Grossmann M, Thomas MC, Panagiotopoulos S, Sharpe K, Macisaac RJ et al. Low testosterone levels are common and associated with insulin resistance in men with diabetes. J Clin Endocrinol Metab 2008; 93: 1834-40.

32 Janssen I, Katzmarzyk PT, Ross R. Body mass index, waist circumference, and health risk: evidence in support of current National Institutes of Health guidelines. Arch Intern Med 2002; 162: 2074-9.

33 Atlantis E, Martin SA, Haren MT, O'Loughlin PD, Taylor AW et al. Demographic physical and lifestyle factors associated with androgen status: the Florey Adelaide Male Ageing Study (FAMAS). Clin Endocrinol 2009; 71: 261-72.

34 Svartberg J, Jorde R. Endogenous testosterone levels and smoking in men. The fifth Tromso study. Int J Androl 2007; 30: 137-43.
35 Atlantis E, Martin SA, Haren MT, Taylor AW, Wittert GA. Lifestyle factors associated with age-related differences in body composition: the Florey Adelaide Male Aging Study. Am J Clin Nutr 2008; 88: 95-104.

36 Forbes GB, Reina JC. Adult lean body mass declines with age: some longitudinal observations. Metabolism 1970; 19: 653-63.

37 Vermeulen A, Goemaere S, Kaufman JM. Testosterone, body composition and aging J Endocrinol Invest 1999; 22: 110-6.

38 Lahti-Koski M, Pietinen P, Mannisto S, Vartiainen E. Trends in waist-to-hip ratio and its determinants in adults in Finland from 1987 to 1997. Am J Clin Nutr 2000; 72: $1436-44$.

39 Vermeulen A, Kaufman JM, Giagulli VA. Influence of some biological indexes on sex hormone-binding globulin and androgen levels in aging or obese males. J Clin Endocrinol Metab 1996; 81: 1821-6.

40 Zumoff B, Strain GW, Miller LK, Rosner W, Senie R et al. Plasma free and non-sexhormone-binding-globulin-bound testosterone are decreased in obese men in proportion to their degree of obesity. J Clin Endocrinol Metab 1990; 71: 929-31.

41 Lee CM, Huxley RR, Wildman RP, Woodward M. Indices of abdominal obesity are better discriminators of cardiovascular risk factors than BMI: a meta-analysis. J Clin Epidemiol 2008; 61: 646-53.

42 Gruson E, Montaye M, Kee F, Wagner A, Bingham A et al. Anthropometric assessment of abdominal obesity and coronary heart disease risk in men: the PRIME study. Heart 2009; 96: 136-40.

43 de Ronde W, van der Schouw YT, Muller M, Grobbee DE, Gooren LJ et al. Associations of sex-hormone-binding globulin (SHBG) with non-SHBG-bound levels of testosterone and estradiol in independently living men. J Clin Endocrinol Metab 2005; 90: 15762

44 Vanbillemont G, Bogaert V, de Bacquer D, Lapauw B, Goemaere S et al. Polymorphisms of the SHBG gene contribute to the interindividual variation of sex steroid hormone blood levels in young, middle-aged and elderly men. Clin Endocrinol 2009; 70: 303-10.

45 Allan CA, McLachlan RI. Androgens and obesity. Curr Op Endocrinol Diab Obes 2010 17: 224-32

46 Svartberg J, Agledahl I, Figenschau Y, Sildnes T, Waterloo K et al. Testosterone treatment in elderly men with subnormal testosterone levels improves body composition and BMD in the hip. Int J Impot Res 2008; 20: 378-87.

47 Snyder PJ, Peachey $\mathrm{H}$, Hannoush $\mathrm{P}$, Berlin JA, Loh L et al. Effect of testosterone treatment on body composition and muscle strength in men over 65 years of age. J Clin Endocrinol Metab 1999; 84: 2647-53.

48 Niskanen L, Laaksonen DE, Punnonen K, Mustajoki P, Kaukua J et al. Changes in sex hormone-binding globulin and testosterone during weight loss and weight maintenance in abdominally obese men with the metabolic syndrome. Diabetes Obes Metab 2004; 6: 208-15.

49 Hammoud A, Gibson M, Hunt SC, Adams TD, Carrell DT et al. Effect of Roux-en-Y gastric bypass surgery on the sex steroids and quality of life in obese men. $J$ Clin Endocrinol Metab 2009; 94: 1329-32.

50 Pasquali R, Vicennati V, Scopinaro N, Marinari G, Simonelli A et al. Achievement of near-normal body weight as the prerequisite to normalize sex hormone-binding globulin concentrations in massively obese men. Int J Obes Relat Metab Disord 1997; 21: 1-5.

51 Ferrini RL, Barrett-Connor E. Sex hormones and age: a cross-sectional study of testosterone and estradiol and their bioavailable fractions in community-dwelling men. Am J Epidemiol 1998; 147: 750-4.

52 Leifke E, Gorenoi V, Wichers C, Von Zur MA, Von BE et al. Age-related changes of serum sex hormones, insulin-like growth factor-1 and sex-hormone binding globulin levels in men: cross-sectional data from a healthy male cohort. Clin Endocrinol 2000 53: 689-95

53 Feldman HA, Longcope C, Derby CA, Johannes CB, Araujo AB et al. Age trends in the level of serum testosterone and other hormones in middle-aged men: longitudinal results from the Massachusetts male aging study. J Clin Endocrinol Metab 2002 87: 589-98.

54 Harman SM, Metter EJ, Tobin JD, Pearson J, Blackman MR Longitudinal effects of aging on serum total and free testosterone levels in healthy men. J Clin Endocrinol Metab 2001; 86: 724-31.

55 Couillard C, Gagnon J, Bergeron J, Leon AS, Rao DC et al. Contribution of body fatness and adipose tissue distribution to the age variation in plasma steroid hormone concentrations in men: the HERITAGE Family Study. J Clin Endocrinol Metab 2000; 85: 1026-31.

56 Morley JE, Patrick P, Perry HM 3rd. Evaluation of assays available to measure free testosterone. Metabolism 2002; 51: 554-9.

57 Handelsman DJ. Testosterone: use, misuse and abuse. Med J Aust 2006; 185: 436-9. 